$\cos$

TRANS · NÚM. I2 $\cdot 2008$

DOSSIER $\cdot 94-120$
En las dos últimas décadas, la historiografía venezolana ha propuesto una relectura de algunos de los eventos del proceso de independencia como resultado del influjo de representaciones extranjeras y de complejos intereses políticos y económicos que determinaron la participación de hombres públicos y letrados. Sobre estos nombres son escasos los análisis que los consideren, más allá de su función individual, como cuerpo político-social y cultural que mediante la traducción genera redes de comunicación y sociabilización, ejercicio lingüistico, a nuestro parecer, determinante para comprender la visión que se hace desde/sobre la Venezuela de principios del siglo xIx. Este trabajo busca identificar la prensa extranjera referida en la Gaceta de octubre de 1810 a julio 1811, las redes de sentido establecidas por la interpretación intra e interlingüística y su influjo en la consolidación de valores e imaginaros sociales en los meses previos a la independencia venezolana.

PALABRAS CLAVE: traducción, prensa, intertextualidad, preindependencia, Gaceta de Caracas.

\title{
Traducción de la prensa extranjera e intertextualidad en el periodo preindependentista de la Gaceta de Caracas
}

Maria Gabriela Iturriza

Universidad de Montreal
In the last two decades, Venezuelan historiography has proposed the rereading of some of the events of the independency process, as a result of the influx of foreign representations and of complex political and economic interests which determined the participation of public men and literati. Very few analyses take them into consideration, beyond the individual roles that they play as a social, political and cultural entity which generates communication and socialization webs through translation. This linguistic exercise seems determinant when it comes to understanding the vision built from and about Venezuela in the beginning of the $19^{\text {th }}$ century. This work tries to identify the foreign press referred in the Gaceta between October $11^{\text {th }} 1810$ and July 1811, as well as the meaning webs established through linguistic interpretation and the incursion of the press in the consolidation of social values and imaginaries during the months previous to the Venezuelan independence.

KEY WORDS: translation, press, intertextuality, pre-independence, Gaceta de Caracas. 


\section{INTRODUCCIÓN}

En la historiografía de la prensa venezolana dos estadios de análisis dedicados al estudio de la Gaceta ${ }^{I}$ son pertinentes para justificar la selección de nuestro periodo: el primero, la compilación realizada por la Secretaría General de Venezuela en 1964, de investigaciones producidas en los años 30 y 6o, décadas que ocupan la publicación de la primera edición de la Gaceta en 1939, dirigida por Luis Correa y a propósito de los cincuenta años de fundación de la Academia Nacional de la Historia.

Un segundo estadio resulta de la segunda edición en 1960, dirigida por Pedro Grases, motivada por el sesquicentenario de la independencia y que funciona como base para la tercera edición, donde se tratan los «estudios preliminares» para cada periodo en la versión facsimilar, también publicada por la $\mathrm{ANH}$ en conmemoración del Bicentenario de Simón Bolívar en 1983 y que contiene nuevos ejemplares de la Gaceta encontrados en I980.

En la compilación del '64 autores como Ávila (1964b), Grases (1964), Boada Alvins (1964) y Ratto Ciarlo (1964), coinciden en que los cambios drásticos en el periodismo venezolano surgen a partir del is de abril de I8ro con la conformación de la «Junta Suprema Conservadora de los Derechos de Fernando VII». Al respecto Grases refiere:

Desde la Gazeta en la que se estampó la noticia del is de abril se venía expresando, en progresión evidente, la decisiva voluntad de separarse del poder de España. Antes de la Gazeta de 9 de julio, no hay, ni mucho menos,

I En lo sucesivo, utilizaremos la versión facsimilar publicada por la Academia Nacional de la Historia en 1983 titulada Gaceta de Caracas. El cambio de Gazeta a Gaceta lo realiza en I815, en el periodo realista, el director del periódico José Domingo Díaz.

la diferencia sustancial que hemos observado en los números anteriores a la del i9 de abril. $\mathrm{Al}$ contrario, las reiteradas manifestaciones de total-liberación chocan más bien con el hecho histórico de haberse publicado durante el gobierno de la Junta Conservadora de los Derechos de Fernando VII (Op.cit., 49).

Casi veinte años después, Grases (1983) refiere que a partir de octubre se consolida la función política del periódico y Pérez Vila (1983) si bien coincide en los cambios producidos a partir de I8Io, señala, lejos de la visión homogeneizante, la diferencia que pudiera existir entre los redactores aun en periodos en los que se persigan los mismos fines.

En este sentido, otros periódicos con metas afines salen a la luz pública: el io de noviembre de i8ro comienza el Semanario de Caracas, impreso por Juan Baillío y destinado a difundir ideas independentistas y, en I8II, salen al público otros semanarios como el Patriota de Venezuela, redactado por Vicente Salias y Antonio Muñoz Tébar, el Mercurio venezolano, según García Chuecos (1964) «segundo periódico nacional», publicado en enero a cargo de Francisco Isnardi, y luego el Publicista de Caracas, órgano del Congreso $^{2}$, cuya publicación para Grases (1983) se debió a la «desazón» de los dirigentes políticos sobre la forma de informar de este periódico. De esta forma, los resultados que se exponen a continuación en cuanto al ejercicio de la traducción en prensa desde una óptica sincrónica son base para establecer a futuro estudios comparativos entre este periódico y los otros de ideales independentistas en I8II o bien como análisis contrastivo de este primer periodo, que va desde abril de r8ro a julio de I8I2 (con la capitulación de Francisco de Miranda ante Monteverde) con los subsiguientes periodos patrióticos de la

2 La Gaceta es órgano del Poder Ejecutivo. 
Gaceta que van desde el triunfo de la «Campaña Admirable» de Bolívar a partir de agosto de I8I3 hasta junio de I8I4 (derrumbe del gobierno emancipado); y el tercero y último, desde el segundo semestre de I82I, luego de la Batalla de Carabobo hasta el 3 de enero de 1822 cuando, según Grases (1983) «se decide su extinción» (Op.cit., XLIII) y se decide la sustitución de ésta por un nuevo vocero de la voz oficial el Iris de Venezuela; fecha en la que la Gaceta de Caracas contaba ya con trescientos números ${ }^{3}$.

Desde esta periodicidad, este artículo conforma una etapa inicial que identifica la prensa extranjera cuyo influjo contribuye a la construcción de la identidad americana en la Gaceta de la Venezuela preindependentista. Desde el marco ideológico, en este proceso nos interesa identificar en parte del primer periodo patriótico (octubre I8Io-julio I8II) cuáles son los periódicos extranjeros que, como intertextualidad, utilizan los letrados e intelectuales en la Gaceta de Caracas como fuente para conformar, mediante la recurrencia de temas, una opinión pública que apoye las nuevas razones políticas del periódico. En ellos interesa determinar, primero, en qué medida la traducción es una vía de fuga a la censura impuesta por la Regencia española para I8Io; segundo, cuáles son los lugares de enunciación de quienes allí participan y tercero, qué temas o representaciones se construyen desde esos distintos espacios. En cuanto a las traducciones es importante poner en relieve cómo se trata el discurso referido en ellas y la relación entre el acontecimiento referido y el anonimato.

En esta etapa arqueológica de la investigación es difícil establecer aún comparaciones entre los textos originales y las traducciones referidas en la Gaceta de Caracas para identi-

\footnotetext{
3 La numeración impresa de la Gaceta no es continua.
}

ficar qué estrategias utilizan los traductores, desde los términos empleados por Bastin, Echeverri y Campo (2004), en la «apropiación» del texto, sea porque implica el proceso de «asimilación» del sentido o una adaptación del texto a los valores culturales «de la lengua de llegada», una «deterritorialización» $y$ «reterritorialización» del texto o bien una «manipulación» o «imitación» de éstos. Sin embargo, podemos identificar en qué medida, primero, los traductores pudieran contribuir a la imagen del nuevo hombre venezolano mediante la interpretación de los acontecimientos ocurridos en tierras extranjeras y traducidos a la lengua castellana con fines independentistas y, segundo, cómo se perfila el rol traductor en la prensa como vínculo entre las ideas ilustradas del proyecto modernizador y el imperante requerimiento de la Provincia para instruir al público sobre estos cambios, así como de informarlo acerca de los acontecimientos no sólo de las metrópolis sino también interprovinciales. De esta forma se evidencia el ejercicio del traductor, que en términos de Lépinette $(2003 \mathrm{~b})$, produce su texto con una finalidad social y adecua las significaciones para el receptor cultural de otros territorios. En ese sentido, las «noticias» en tanto acontecimientos referidos también comprenden una forma de lo que Ortiz (200o [1940]) y Rama (1987: 39) definieran como proceso de «transculturación» entendida en este caso también de forma intralingüística, puesto que «la capacidad selectiva no sólo se aplica a la cultura extranjera, sino principalmente a la propia [...] Habría pues pérdidas, selecciones, redescubrimientos e incorporaciones $[\ldots]$ dentro de una reestructuración general del sistema cultural, que es la función creadora más alta que se cumple en un proceso transculturante».

Desde los modelos establecidos por Lépinette 
(2003a) la metodología que empleamos obedece al modelo sociológico-cultural, pues implica la consideración de los contextos de producción y recepción de los documentos, es decir, cómo se «transplanta» el texto en contextos espaciales y temporales diferentes cuya recepción y efectos de este proceso no necesariamente han sido previstos en el momento y en el estadio de producción del texto. Recabamos así datos históricos y socioculturales para el periodo que tratamos, identificamos los discursos utilizados en el texto en el caso de la traducción y en cuáles de ellos aparecen eventualmente comentarios y evaluaciones para determinar el efecto, con fines independentistas (o no) que pudiera adjudicársele al texto en el contexto en el que se inserta la traducción. Desde nuestra óptica es necesario considerar que ésta es una respuesta a los mecanismos de censura para la época pero también es presumiblemente causa de las manifestaciones preindependentistas. En este sentido, un aspecto a considerar en cuanto al texto traducido es la compleja función del redactortraductor de prensa en tanto sujeto histórico, pues no siempre se hallan datos precisos sobre quiénes asumen la traducción de ciertos textos, aunque se trate de un grupo de redactores en particular, y aunque se pueden presumir desde los trabajos de Pino Iturrieta (2000), Langue (2000) y Leal (2002) los grupos de poder a quienes se dirige la prensa, no se identifican explícitamente los receptores «inmediatos» o «diferidos» (en términos de Lépinette, 2003b) aunque se trate de la elite criolla.

\section{Perfil de la Gaceta en la SOCIEDAD VENEZOLANA}

Como bien se conoce en la historiografía que trata la independencia venezolana, los sucesos de Aranjuez y Bayona entre marzo y mayo de I808, las abdicaciones en la monarquía borbónica y las estrategias políticas de Napoleón suscitaron en Venezuela, en octubre de 1808 , la creación de la Gaceta de Caracas como vocero oficial y cuya publicación se debía, según la propia editorial «al espontáneo interes del gobierno, y á la concurrencia de otras autoridades el logro de un establecimiento que por muchos años, ha envidiado Carácas á otras poblaciones de ménos consideración» (24/Io/o8)4. Sobre este «espontáneo» interés referido en la primera editorial de la Gaceta podemos puntualizar a partir de Grases (1983) «el propósito oficial muy apasionadamente decidido», del Capitán General de Venezuela, don Juan de Casas 5 , el Intendente del Ejército, don Juan Vicente de Arce y el «acaudalado comerciante» Francisco González de Linares, de quien dependerán las diligencias para la importación de la imprenta a Venezuela. Es la relación entre la política oficial y el comercio lo que determina gran parte de las noticias publicadas en la Gaceta, sumado a la circulación de papeletas, manuscritos e impresos que incitaban a la independencia en una nación donde la elite criolla pretendía la adquisición de mejores cargos en relación con los peninsulares ${ }^{6}$.

El eclecticismo en una sociedad que se debate entre el proceso modernizador y los valores de la tradición colonial no nos permite sostener la

4 En lo sucesivo se respeta la grafía de la época y, por la compleja numeración de la Gaceta en algunos periodos, reseñamos sólo su fecha de publicación.

5 Juan de Casas y Barrera, militar español y Capitán General de Venezuela desde el 9 de octubre de 1807 hasta el I9 de mayo de I809 cuando sustituye, por orden de Carlos IV, a Manuel de Guevara Vasconcelos. Será sucedido luego por Vicente Emparan.

6 Sobre la participación de los criollos en la burocracia colonial refiere Lynch (200r: 82) «los americanos deseaban un cargo por varias razones: como una carrera, una inversión para la familia, una oportunidad para adquirir capital y un medio de influir en la política de sus propias regiones en su propio beneficio». 
interpretación maniquea de eventos planteados en términos de una elite que, por una parte, sostiene un sistema de gobierno siempre y cuando pudieran tener una participación más activa y, por otra, la existencia de una elite que difunde un ideario independentista a favor de la igualdad de derechos (que resulta ser, precisamente, entre americanos -de elite-, peninsulares y españoles); en tal caso "grosso modo" pensamos en grupos de poder cuyas acciones derivan en tres efectos principalmente, según Picón Salas (1984: 53) el de los «inmóviles», que «deben formar el cuerpo conservador de Fernando VII [citado en original] y en el fondo desean que poco o nada se cambie»; los «tranquilos juristas» que «estando de acuerdo, en principio, en la autonomía, desean que ésta se realice de manera prudente» y el de los «revolucionarios», que «quieren romper de raíz con el pasado y crear el nuevo orden y estado de cosas».

La Gaceta de Caracas, dirigida a estos grupos y referida generalmente como el primer periódico o «antiperiódico» venezolano (Ávila, 1964a), se publica con la imprenta comprada en Trinidad por Mateo Gallagher y James Lamb y da cuenta de la pugna y alternancia entre el gobierno realista y el patriota independentista desde el 24 de octubre de 1808 (época de dominio realista) hasta el 3 de enero de 1822 (época republicana). Según Machado (1964), los sucesos de Bayona son conocidos en Caracas a través de The Times de Londres, lo que suscita en la Provincia de Caracas manifestaciones de fidelidad a la casa de Borbón y a Fernando VII. Ávila (I964a: 9) especifica, además, que esta Gaceta se creó gracias «a la influencia de Inglaterra ante el Capitán General Casas ${ }^{7}$ para que diera a conocer los atropellos de Napoleón

\footnotetext{
7 Díaz Sánchez (1964:26) justifica la petición de Casas no por intereses políticos sino porque «la cultura de la Provincia no le era indiferente».
}

en la Península»; como también señala «la sugerencia de Inglaterra, aliada del Imperio Español y dispuesta a sacar partido de todo río revuelto, tuvo más peso [...] que todo el montón de peticiones criollas empolvadas en un viejo armario» y agrega: «es necesario recalcar que los primeros dueños de la imprenta fueron dos ingleses» (Ávila, I964b: 3I).

Para efectos de la historiografía de la traducción, importa mencionar según Bastin e Iturriza (en la presente edición) a partir de los hallazgos de Leal (2002: II) la publicación que se constata como «primer periódico de Venezuela»: el Courier de la Trinité Espagnole, fechado el jueves I3 de agosto de $1789^{8}$, editado en Puerto España presumiblemente por F. Jean Willox en francés y castellano y clausurado por «difundir noticias subversivas de la Revolución Francesa».

La Gaceta de Caracas como muchas de las que se publican en las posesiones de ultramar, además de funcionar como vocero oficial con Andrés Bello como primer redactor, exhorta a los lectores, «ilustres habitantes», a reconocer la utilidad de este órgano «no solo baxo los puntos de vista que ofrecen la Agricultura y el Comercio, sino también la Politica y las Letras», por lo que se «suplica» a contribuir «á la instrucción publica y a la inocente recreación que proporciona la literatura amena» (24/ז0/08).

En cuanto al impreso, la Gaceta cuenta desde sus inicios con cuatro folios a doble columna y

8 Periódico de dos columnas y cuatro páginas, de aparición quincenal bajo la locución latina del Arte poética de Horacio "Omne tulio punctum qui biscuit utile dulce». Este periódico se imprimió en Trinidad, que era parte todavía de Venezuela antes de la ocupación inglesa en 1797. Como menciona Leal (2002) se conocen cinco números, el primero con fecha I3 de agosto de 1789 y el quinto ro de noviembre del mismo año, de los cuales dos (el i y el 5) se localizaron en el Archivo General de Indias (AGI). Ya en el trabajo de Langue (2000), se hace referencia a la existencia de este periódico en investigaciones hechas por Leal en 1985 . 
con cuatro secciones: la primera, que da a conocer las noticias de España, la segunda, los sucesos en Europa y los movimientos de Napoleón, la tercera, noticias sobre la Provincia y cuarta, avisos de venta, querellas, huidas de esclavos, oferta de servicios, etc. Es la última columna el espacio destinado, en el primer periodo realista, para las dos últimas secciones.

Podemos notar luego ciertas variaciones; por ejemplo, la asignación de un espacio inicial en ocasiones sin título ( $\mathrm{y}$ dependiendo de los acontecimientos), destinado a comentarios del «redactor» (Andrés Bello) sobre el contexto peninsular o local o bien la sección que desde sus inicios notifica sobre los eventos en España. En las ediciones que van luego del abril de I8Io se destinan las primeras tres columnas a las noticias sobre Europa y, en la sección sobre noticias locales de la Provincia (segunda columna de la tercera página), se nota la inserción de cartas, reflexiones o extractos de prensa extranjera sobre los acontecimientos en Venezuela, sección que en ocasiones comienza a partir de la segunda columna del segundo folio, de manera que notamos una evidente cesión del espacio a quienes de alguna forma se hacen intérpretes de los eventos locales, cuyas reflexiones se evidencian en el incremento de la circulación de exhortaciones, proclamas y manifiestos preindependentistas americanos, a partir del ejemplo «que Caracas dio», entre ellos el de Santa Fe, el Nuevo Reyno de Granada y Buenos Aires, etc.

En cuanto a su extensión, Grases (1983) apunta a que ésta amplía al equivalente de siete páginas a partir de $\mathrm{I} 8 \mathrm{II}^{9}$ y notamos que desde noviembre la Gaceta pasa de dos a tres columnas, lo que concede mayor espacio para

9 Según Grases (1983) el formato de I808 a r81o es de 4 páginas de $27 \mathrm{cms}$. de alto y en I8II tiene $32 \mathrm{cms}$. de alto y tres columnas. la difusión de las ideas patrióticas pero, aunque convertido de semanario a bisemanal fue «el único que, por su carácter oficial, no podía satisfacer todas las tendencias, mucho menos a las radicales, que recurrieron a otros medios, a las hojas clandestinas lanzadas contra realistas, timoratos, reaccionarios...» (Ratto Ciarlo, I971: 43).

\section{CONTROL, OPINIÓN PÚBLICA Y CONCIENCIA SOBRE EL LECTOR}

En la edición del 27/04/ro, días después de la formación de la Junta Suprema de Caracas, la Gaceta destaca, bajo la divisa «Salus populi suprema lex esto», dos aspectos recurrentes en este periódico a partir de octubre: la denuncia por el control de la información por parte de la Regencia y la imperiosa necesidad de contar con otros aliados que favorecieran la causa patriótica, razón que se observará favorecida ante el inminente influjo de papeles y cartas que comienzan a publicarse en Venezuela llegadas del exterior, tal como ya se exhortaba, por ejemplo, en la edición del 27 de abril de i8ro:

Quando las sociedades adquieren la libertad civil que las constituye tal es quando la opinión pública recobra su imperio y los periodicos que son el organo de ella adquieren la influencia que deben tener en lo interior $\mathrm{y}$ en los demas paises donde son unos mensajeros mudos, pero veraces y energicos que dan y mantienen la correspondencia reciproca necesaria para auxiliarse unos pueblos á otros. La Gazeta de Caracas destinada ahora á fines que ya no estan de acuerdo con el espiritu público de los habitantes de Venezuela va á recobrar el carácter de franqueza y de sinceridad que debe tener $(27 / 04 / \mathrm{ro})$.

La exhortación a una nueva formación de la opinión pública dada por la constitución de la libertad civil apunta a la noción de opinión 
pública en su sentido moderno en tanto función crítica por parte de los lectores. Como bien señala Guerra (2002: 360) se da cabida a la "publicación» por cuanto «la iniciativa de la palabra viene ahora de la sociedad» y no por el «atributo de las autoridades del antiguo régimen», ejercido en Venezuela por Juan de Casas, máxima figura gubernamental para el periodo de aparición de la Gaceta en 1808. Es precisamente este régimen el que hace evidentes las consignas sobre la censura: «se dá al Publico la seguridad de que nada saldrá de la Prensa sin la previa inspección de las personas que al intento comisione el Gobierno, y que por consiguiente en nada de cuanto se publique se hallara a menor cosa ofensiva a la Santa Religión Catolica, a las Leyes que gobiernan el pays, á las buenas costumbres, ni que pueda turbar el reposo ó dañar la reputacion de ningun individuo de la sociedad» (-énfasis en original- 24/ro/o8). Se daba entonces en los inicios del periódico importancia a la «publicidad' en términos de Habermas (I997) a los atributos y notoriedad de las personas en la vida pública. No obstante, el control explícito en la editorial, escrita según Grases (1983) por Andrés Bello, fue lo que hizo dudar a la crítica en los años 70 sobre la autoría de éste y, autores como Ratto Ciarlo (I97I), afirman que fue ésta la motivación para que Bello, junto con Isnardi, pensaran en I809 en la revista Lucero, independiente de la atadura oficial.

En ninguno de estos casos podemos afirmar que la prensa es más o menos informativa o de opinión, tendencias que obedecen al parecer a los estados de urgencia en España y la Provincia, pero tanto en la época realista como la patriótica (en tanto proceso de ruptura con la metrópoli), la Gaceta trata una función persuasiva hacia un lector orientado, que en la primera edición de 1808 supone un público homogéneo, mientras que en la de I8ro, que inicia el periodo patriótico, se hace evidente la disidencia en la opinión pública, en desacuerdo con «el espíritu público de los habitantes», como se menciona en la edición del 27 de abril de i8ro. Este espíritu público se hacía explícito en prensa, por ejemplo en la época realista, con los donativos de los «Vecinos de la Provincia de Caracas» que se relacionan «con motibo de la Invasión intentada por Miranda contra las de Venezuela, y aplicados à las actuales urgencias del Estado en Europa» (28/o4/og) o bien en la edición previa al i9 de abril de i810, cuando se hacen donativos a la Casa de León en Maracay para los objetos de la Comisión Real, «revelación de fuero para este objeto patriótico» (el del heroísmo español frente a Bonaparte). Aunque no podamos establecer con exactitud una genealogía de nombres que pertenecen a esa comunidad interpretativa que refiriera Anderson (1993) para explicar la forma en que una nación es imaginada, sí podemos afirmar la heterogeneidad de intereses políticos en los lectores, al menos en aquellos que constituyen la elite criolla.

Es la «comunidad», según Anderson (1993) como «compañerismo profundo» o el «sentimiento de comunidad» (Guerra, 2002) de quienes tienen derecho a la palabra en prensa y hacen uso del «espacio global de comunicación» lo que permite, como bien apunta Guerra, la manifestación de la angustia por no recibir noticias de la península; que en el caso venezolano da pie para presentar una relación familiar contra el adversario Napoleón «En la escacez actual de noticias autenticas no será desagradable al público informarse [...] de la familia, cuya usurpada exaltación ha sido tan costosa a la humanidad» (28/04/og).

Un año después, con la editorial y dirección, a cargo de Isnardi y Roscio, éste último expresa: «El Público ha visto y leido ya el acta primitiva de nuestra regeneración política $[. .$.$] por con-$ siguiente, debe empezar à instruirse metodicamente de todas las demas deliberaciones con 
que la Suprema Junta ha procurado hasta ahora llenar dignamente la confianza que el Pueblo ha depositado en ella, para que todos sepan lo que conviene à todos y no haya quien no se penetre de la confianza que debe inspirar tan manifiesta unanimidad de sentimientos» (27/04/ro).

En cuanto al pueblo como destinatario, éste no pareciera tratarse de una sociedad «plebeya» en términos de Habermas (I997) ni de las capas bajas que refiere Leal (2002) sino, como lo concibiera meses después José Miguel Sanz en el Semanario de Caracas como uparte esencial de la constitución; a diferencia de que, obrando en cuerpo tumultario, es tirano quando se junta, y quando se disuelve esclavo» (6/ז2/ıo) o bien como lo señala en la edición del Semanario del 23/ז2/Io:

En un sentido mas propio y riguroso la voz Pueblo solo comprende á los que teniendo propiedades y residencia se interesan por ellas en la prosperidad de la cosa pública, pues los que nada tienen solo desean variaciones ó innovaciones de que puedan sacar algun partido favorable. En una Republica ó Reyno bien organisado son los propietarios los que componen el Pueblo Soberano [...] Aristóteles habia dicho lo mismo explicando las voces populus y populares multitudo (Sanz; 1959: 58) ${ }^{\text {Io }}$.

Si bien la posición de Sanz pudiera responder a la de la elite moderada es José Domigo Díaz, también redactor del Semanario y luego partícipe de la causa realista, quien concibe de otra forma al pueblo. En un artículo suyo sobre «Comercio y Agricultura» en la edición del 8/1I/ro refiere «la última clase del pueblo que siendo la más numerosa, es la que constituye la clase principal de la sociedad, es á quien mas interesa este intimo conocimiento [de moderar los gastos en la comunicaciones entre los pueblos], porque es la

ro Seguimos la edición del Semanario de la Academia Nacional de la Historia publicada en 1959. En ésta se siguen idénticamente los números de página de la versión original. que mas padece»(Díaz, I959: 7); de manera que el pueblo como estrato social no comprende al lector ideal y se le excluye de las formas de representación generalmente escogidas por el discurso hegemónico de la prensa de la época.

Ahora bien, cuando Roscio trata «la instrucción metódica» de las liberaciones con que la Junta otorga la confianza al Pueblo, no podemos establecer si se refiere a una incipiente libertad de prensa o la que ocurre, un año después, con la libertad de imprenta ya que, según Ratto Ciarlo (197I) en el contexto venezolano de 1806 se tenía prohibida la impresión de dos obras: Los Derechos del hombre y del ciudadano de Juan Bautista Picornell que no sale sino en I8II por la imprenta de Juan Baillío y La lógica o los primeros elementos del arte de pensar del abate Condillac, que se reimprime un año después.

Para Boada Alvins (1964) «en Venezuela la expresión del pensamiento estaba restringida por una estricta censura que aplicaban con simultáneo celo las jerarquías civil y religiosa» (54). No es sino hasta el I de julio de I8II, cuando la sección legislativa promulga el primer Reglamento de la libertad de la Imprenta, publicado en la edición del 25/o7/Ir del Publicista de Caracas (dirigido por Isnardi) ${ }^{\text {II }}$. Este reglamento concede a la imprenta «el canal más seguro para comunicar á todos las luces» y «un medio de ilustrar á los Pueblos ${ }^{12}$ en sus derechos» además de restringir «los escritos subversivos del sistema adoptado y establecido en Venezuela el qual consiste principalmente en su independencia y soberanía $»^{{ }^{3}}$ (Op. cit. art. 8: 29). Sin embargo, el I8II.

II Se publica también en la Gaceta el 6 de agosto de

I2 Pérez Vila (1983) compara la diferencia entre la redacción del Reglamento de la libertad de imprenta de las Cortes de Cádiz, donde la libertad es un medio de ilustrar a la «Nación» y no al «Pueblo», como aparece en la trascripción hecha en Caracas.

r3 Se transcribe textualmente la grafía. 
Reglamento también funcionaría como instrumento de control pues, como expresa el artículo I6 $6^{\circ}$ se prohibía a cualquiera no autorizado por el gobierno a poseer una imprenta y quienes abusaran de esta libertad «no solo sufriran la penas señalada por las leyes, según la gravedad del delito, sino que este, y el castigo que se les impongan, se publicarán con sus nombres en la gazeta del gobierno»; además de castigar, según el artículo $16^{\circ}$ "con el último suplicio» a quienes contravinieran el sistema adoptado.

La divulgación del Reglamento de imprenta se vincula, para autores como Ratto Ciarlo, a las publicaciones de William Burke en la Gaceta $^{\mathrm{I}}$, principalmente por el artículo sobre la tolerancia religiosa del 19/o2/Ir. Según Burke en nota al pie, este artículo es «orden del discurso [que] ha obligado al autor [...] tratar una materia tan delicada $[. .$.$] con la esperanza de que el res-$ petable Clero y el Pueblo Americano, no verán en sus raciocinios, sino un deseo de restablecer la mas pura caridad cristiana», lo que origina respuestas inmediatas como las Impugnaciones de Antonio Gómez en la Gaceta, las de Antonio Picón y Mariano Talavera o en $1812^{15}$, la respuesta de la Real y Pontificia Universidad de Caracas sobre La intolerancia politicoreligiosa, vindicada; o refutación del discurso que a favor de la tolerancia religiosa, publico D Guillermo Burke, en la Gazeta de Caracas, del Martes in de febrero de I8II, No. 20».

A propósito de esta diatriba y como comenta Ratto Ciarlo, la Gaceta publicó el 26/04/II con la idea de "crear atmósfera» el Reglamento de Libertad de Imprenta en España (producto de las Cortes de Cádiz en septiembre de I8Io), seguido de un Artículo comunicado en inglés

I4 Los Derechos de la America del Sur y Mexico, sección que inicia el 23/rI/ro.

I5 Sobre la fecha de edición, Grases (I979) hace énfasis en la irregularidad del número 2 de la data «I8I2». (traducido) donde se expone: «no dudo que los lectores comprenderán de antemano, que los manuscritos examinados por mi, son los de Mr. Bentham». Al día siguiente, el 30 de abril de 103 I8II, se inserta en las columnas de la Gaceta las Reflexiones sobre la libertad de imprenta, cuya fuente es El Español en su edición número IX, dirigido por José María Blanco White desde Londres. Sin embargo, ha pasado inadvertidamente para los estudiosos de la Gaceta, que las inserciones que se hacen en ella del periódico El Español desde octubre, cuando se critican las desatenciones que hacen las Juntas sobre la opinión del pueblo, tratan sobre «la indispensable libertad de la imprenta» para «ratificar la opinión de un Pueblo» (I6/ro/ro); de manera que pareciera ser Blanco White, en calidad de redactor-colaborador de la Gaceta uno de los principales que abogan por este derecho.

Si bien en el manuscrito de noviembre hace referencia a una de sus fuentes, la dificultad para la detección de éstas en la redacción de eventos o expresiones patrióticas radica en que el público cuenta con información implícita y lecturas propias de la época, muchas de ellas vinculadas a los artículos de prensa, de manera que la intertextualidad en ésta es tácita en muchos de sus discursos. En este sentido, la circulación de manuscritos e impresos conforman un vasto corpus por lo que referiremos en esta fase de resultados solamente aquellos en los que se hagan referencias en otras lenguas, haya cambios explícitos en el discurso o haya relación entre el texto y otros en los que sea evidente su traducción o fuente extranjera.

\section{LA PRENSA EXTRANJERA COMO FUENTE TRADUCIDA Y NOTICIOSA}

Desde octubre de 1809, un semestre antes de la conformación de la Junta Suprema Conser- 
vadora de Caracas el in de abril, las noticias impresas en espacio de superficie se dedican más a dar cuenta sobre Europa y España mediante la 104 Gazeta de Cádiz, la Gazeta de Sevilla y la Gazeta de Gibraltar además de dos menciones a la Gazeta de Barbada (27/04/io. y I6/o9/ıo). Es a partir del i9 de abril de i8ro cuando encontramos referida la prensa extranjera y en algunas de ellas se apunta el incipiente deseo independentista; por ejemplo, en la edición de la Gaceta del r8/o5/1o se trata a partir del periódico inglés Le Courier la determinación de la Provincia de Caracas a no ser víctimas del despotismo y el 29/o6 trata el ejemplar del The New York Gazette (del martes 22 de mayo) donde se lee sobre la posibilidad de que en La Habana se establezca un gobierno independiente si los franceses tenían progresos en España. El 6/o7 se relacionan algunas gacetas que han llegado «al Gobierno», la gazeta inglesa The Morning Post y Barbados Mercury (del Caribe) y en la edición del 20/o7/Io se refiere un periódico estadounidense: The Evening Post, que en el 4 de junio trata noticias sobre Baltimore, entre las que expresa este periódico «Nuestra sorpresa (dice el Evening Post) ha sido sumamente agradable al ver à la cabeza de la Gazeta de Caracas el siguiente mote Salus populi suprema lex esto. La salud del pueblor es la suprema ley, substituido á la tiránica divisa Yo El Rey ordeno y mando, con que el despotismo ministerial abusaba en la America del nombre del Monarca para oprimir a sus vasallos».

Con su epígrafe «Salus populi...», el periódico caraqueño encabezaba su edición como se conoce, con las palabras de la proclama de Francisco de Miranda en I806 y también refería, como explica Grases (1983), a la divisa del periódico liberal de la península $E l$ voto de la nación española, cuyo prospecto detalla Andrés Bello

I6 Énfasis mío. (presumiblemente) ${ }^{\mathrm{I7}}$ en la edición del 16/02/10 bajo la sección «literatura patriótica»; de manera que el influjo de papeles que prosiguen esta causa es previo, aunque con poca frecuencia, al ig de abril. Sin embargo, es pertinente destacar que cuando se realiza la traducción de la divisa en la edición de febrero, antes de la formación de la Junta de Caracas en abril de I8Io, el epígrafe es traducido «la salud del Estado como suprema ley», a diferencia de la traducción citada textualmente del periódico estadounidense.

Es en octubre de I81o cuando se hace más evidente el contraste entre las noticias provenientes de la representación del Consejo de Castilla y las Cortes de Cádiz, relativas a los fines patrióticos, y las que refieren los procesos locales americanos, incluyendo entre ellas las publicadas por prensa extranjera, ahora citada como fuente. A partir de ese momento, la Gaceta cede sus espacios a cuatro periódicos en lengua castellana: el Español publicado en Londres, dirigido por José María Blanco White ${ }^{\mathrm{r}}$, liberal y cuya primera edición se publica el 31/08/10 ${ }^{19}$ en la Gaceta. Sin embargo, no podemos afirmar que este periódico y los que siguen a continuación, por ser publicados en castellano, estén exentos de haber traducido algunas de sus noticias, ya que, por ejemplo, encontramos entre las noticias de la Gaceta algunas provenientes de $E l$

${ }^{17}$ Pérez Vila (1983) adjudica esta traducción a Bello.

I8 Guerra (2001: 307) atribuye a este periódico la difusión de modelos franceses. Para Guerra, Blanco White (José María Blanco y Crespo) también fue redactor en la parte política de la segunda serie en Sevilla de El Semanario Patriótico que va desde el 4 de mayo al 30 de agosto de I809 y en Londres «supo construir toda una red de corresponsales, muchos secretos».

I9 Para el periodo en cuestión hallamos la colaboración de El Español, en I8Io, los días I6, I2 y 23 de octubre; 6, I6 $\left(n^{\circ} \mathrm{V}\right)$ y 23 de noviembre (éste último sobre los inconvenientes con los números II y III). En diciembre el ir y I4 (se critica la edición $n^{\circ}$ VIII del periódico). Luego el $n^{\circ}$ VII el 5 de abril de I8II y el no IX el 30 del mismo mes. 
Español sobre oficios político-militares de hombres públicos cercanos a Napoleón como Decré y Bassano, que fueron redactados en francés.

También encontramos referencias de la Constitución Feliz (de Santa Fe de Bogotá) el I2/ıo; El Colombiano («periódico español de Londres»), dirigido por Francisco de Miranda, impreso que aparece en la edición de la Gaceta del 20/ri/ro y el 25/or; el Argos Americano (de Cartagena de Indias, publicados los números i y 2) en la edición del 23/rry también el 8/I2/Io; la Gaceta de México, el i8/or y la Gazeta de Buenos Aires el 5/o7/ri. Es la «correspondencia reciproca necesaria» de la que trata la edición del 27 de abril de la Gaceta la que entabla diálogos interprovinciales que establecen en cierta forma «mundos paralelos», en términos de Vidal (1985) al de los otros criollos que se encuentran igualmente construyendo representaciones imaginarias de otros espacios, por ejemplo, las disertaciones que sobre la soberanía se construyen en estos periódicos a partir de los sucesos de i8io.

En cuanto a las traducciones explícitas presentadas por diversos periódicos una breve y primera relación nos permite contextualizar ciertos lugares de enunciación de los que provienen los artículos traducidos, aunque no siempre haya garantía de que un periódico se publique todo en la lengua del país desde donde se difunde; ejemplo de esto es la nota del redactor de la Gaceta en la edición del 5/o7/Ir, quien expresa: «En el periodico [inglés] (The Independent Gazzette,) vendido hace mucho tiempo á nuestros enemigos se lee en muy mal castellano, el siguiente discurso que aunque sin orden ni conexión en sus ideas y principios, contiene calumnias tan groseras que el solo merece el titulo de diatribe con que quiere denigrar las reflexiones que refuta».

Se debe tener en cuenta que en la Gaceta existen, al menos en la sección «Notas extranjeras», diversidad de textos que presentan traducciones sin fuente y que inferimos el ejercicio traductor por el peritexto o relación con otros documentos, por ejemplo en las cartas de Sir John Moore prohibidas por la Regencia. No es sino hasta febrero de I8II cuando se observan incisos que informan sobre la traducción propia o proveniente de otras fuentes, por ejemplo en el texto presentado, al parecer, por el cuerpo editorial-político de la Gaceta que expone el I9/o2/II, a propósito de la Cámara de los Comunes de Inglaterra, lo siguiente:

Se acerca el tiempo de la instalacion del numeroso Cuerpo representativo de los derechos de Venezuela [...] El procedimiento [...] del Parlamento de Inglaterra no puede menos que ser de una gran utilidad a un Pueblo que va à crear un gobierno popular despues de trescientos años de tirania [...] El traductor no pudo fixar la nomenclatura de muchas voces, que nosotros tampoco hemos podido determinar por la escasez de tiempo [...] ¡oxalá mil veces que el Congreso mismo llegue á corregir hasta los nombres, para que nada haya que no tenga el sello y el caracter Américano!

El periodo que se presenta, aún breve para establecer conclusiones definitivas sobre las estrategias traductoras para la construcción identitaria americana, pero extenso en referencias y traducciones, no permite determinar si los redactores de la Gaceta acudían a ciertos periódicos para obtener alguna información sobre ciertas regiones o temas, pero sí nos permite presentar la relación que en muchos casos se establece entre los papeles que se interceptan, publican y difunden a través de la Gaceta y cómo esto repercute en la imagen sobre la construcción del otro como función persuasiva para la búsqueda de la conciencia crítica de los lectores. 
No debe pasar inadvertidamente que las traducciones pueden derivar de una extensa cadena de relaciones; por ejemplo, la edición 106 de la Gaceta de Caracas del 22/04 informa las noticias sobre México a partir de lo que se lee en la Gaceta de Nueva York, traducido por El Monitor de Luisiana. Esta red de comunicación se evidencia también en los extractos de papeles, cartas y artículos mediante las traducciones por el uso del discurso referido; por ejemplo, en las ediciones del 30/10/ıo del Bell's Weekly Messenger se expresa: se dice que el Emperador, Napoleón; el Herald refiere: parece que siendo la opinión de su Nación. Otras formas las redacta el Relf's de Filladelfia el 20/II cuando utiliza: Que la opinión general en Lisboa era que si se aventuraba a retirarse, que habian sido alistados todos; expresiones que buscan otorgar autenticidad a la noticia, como también se demuestra en la edición de la Gaceta del I4/ı2/ıo, cuando se comenta aunque de forma anónima: Por carta de Gottenbourg, los diarios de Paris, Una carta de Burdeos, se dice que la Rusia.

Con el propósito de establecer las relaciones entre las traducciones de los periódicos-fuente de la Gaceta y la inmediatez con que se reproducían o no ciertos números que requerían dicho ejercicio de traducción, relacionamos entre octubre de I8Io-julio I8I los veintiún periódicos y la revista referidos con su fecha de aparición en la Gaceta, así como, de existir la información, la fecha de publicación del ejemplar propiamente.

Para efectos de la identificación de textos traducidos se hace difícil deslindar el vínculo que existe entre las representaciones de políticos en papeles oficiales (interceptados o no) y algunas referencias de la prensa extranjera, por lo que primero estableceremos esta relación en función de las lenguas presentes en los textos: el latín, francés e inglés para identificar en qué

tipos de manuscritos e impresos se insertan las traducciones y a qué textos refieren (intertextualidad); también qué temas tratan y cuáles son sus fuentes. En segundo lugar, planteamos la relación entre los temas tratados y coincidencias en los periódicos en función del contenido noticioso sobre el contexto extranjero, para lo que tenemos en cuenta el evitar falsas causalidades al establecer las redes de información.

\section{TRADUCCIÓN E INTERTEXTUALIDAD. EsTRATEGIAS DE FILIACIÓN POLÍTICA Y RESPUESTAS DISIDENTES A LA CENSURA}

El influjo de otras lenguas además de la castellana se observa en discursos que han sido periféricos en la historiografía tradicional y en los análisis de prensa independentista; por ejemplo la sección de «Avisos» y "Otros», que en la Gaceta dan cuenta sobre los valores de la época. Allí encontramos evidencias de la repercusión que el latín tenía como lengua de y para ilustrados y cuyo contacto con algunos sectores sociales, «invisibles» en la construcción hegemónica del discurso, pareciera haber producido en éstos cierta necesidad de accesibilidad o participación. Así, en la edición del 5/03/Ir se detallan las características del huidizo negro criollo José Pablo, quien de "genio inactivo [...] sabe leer y escribir, y preciado de su erudición, ò excitado por el licor, se exercita muy a menudo en cantar latin» o bien, un mes después, se ofrecen con la aprobación del Supremo Gobierno las «Clases de Latinidad [...] cuyo principal intento es el de enseñar sin interés alguno, á todos los pobres» (22/04/II). En esta sección observamos también un solo ejemplo del ejercicio traductor, por ejemplo, el «Aviso» de la dirección del señor Don Juan Romney, facultativo, quien vive «en la calle de Juan numero 40 o en Ingles como ahí se nombra numero 40 John Street» (7/og/ro). 


\section{Relación de periódicos y revistas-fuente en la Gaceta}

Periodo octubre I8Io - julio I8II

\begin{tabular}{|c|c|c|c|c|}
\hline Periódico & Procedencia & $\begin{array}{l}\text { Primera aparición } \\
\text { en la Gaceta } \\
\text { (oct.181o-jul. I8II) }\end{array}$ & $\begin{array}{l}\text { Fecha/No. del } \\
\text { ejemplar }\end{array}$ & Observaciones \\
\hline $\begin{array}{l}\text { Bell's Weekly } \\
\text { Messenger }\end{array}$ & Londres & 23/10/10 & $\begin{array}{l}\text { Monday' } \\
\text { edition } \\
2 \text { julio, I8ro }\end{array}$ & $\begin{array}{l}\text { También en Gaceta en las edi- } \\
\text { ciones del 30/IO/IO, 30/II/Io y } \\
\text { 31/o5/II con ejemplar del 3/o2/II. }\end{array}$ \\
\hline The Herald & $\begin{array}{l}\text { New York } \\
(\text { ¿? })\end{array}$ & 30/10/10 & No. 28 & $\begin{array}{l}\text { El lugar se infiere por la inser- } \\
\text { ción que se hace en Gaceta el } \\
\text { o2/o7 del New York Herald. }\end{array}$ \\
\hline $\begin{array}{l}\text { Morning } \\
\text { Chronicle }\end{array}$ & Londres & 6/1I/IO & 5/o9/10 & $\begin{array}{l}\text { También en Gaceta el I3/II/Io } \\
\text { con ejemplares del 3I e (ilegible) } \\
\text { de marzo. } \\
\text { E1 II/I2 con ejemplar del 2I/o9. } \\
\text { En Gaceta el 25/12 con ejemp. } \\
\text { del I7/o9 } \\
\text { E1 I/o2/Ir sin fecha de ejemplar } \\
\text { E1 I5/o2 con ejemplar del } \\
\text { I7/I2/Io }\end{array}$ \\
\hline
\end{tabular}

\begin{tabular}{|c|c|c|c|c|}
\hline $\begin{array}{l}\text { Relf's } \\
\text { Philadelphia } \\
\text { Gazette }\end{array}$ & Filadelfia & 20/II/IO & $\mathrm{s} / \mathrm{e}$ & $\begin{array}{l}\text { También en Gaceta el I/oI/II con } \\
\text { ejemplar del 21/II/IO. } \\
\text { E1 22/o4/II con ejemplar del } \\
\text { 23/o3/II. } \\
\text { E1 I4 y el 2I/o5, ambos sin refe- } \\
\text { rencia de los ejemplares. }\end{array}$ \\
\hline Times & Londres & I3/II/1O & $\begin{array}{l}\text { 3I, (ilegible) } \\
\text { de marzo }\end{array}$ & $\begin{array}{l}\text { También en Gaceta el 20/ı/ıo } \\
\text { sin referencia de ejemplar. }\end{array}$ \\
\hline $\begin{array}{l}\text { The Public } \\
\text { Ledger }\end{array}$ & Filadelfia & 20/II/IO & $\mathrm{s} / \mathrm{e}$ & Sin otra referencia en la Gaceta. \\
\hline $\begin{array}{l}\text { Philadelphia } \\
\text { Mercantile } \\
\text { Advertiser }\end{array}$ & Filadelfia & 23/1I/10 & $\mathrm{s} / \mathrm{e}$ & 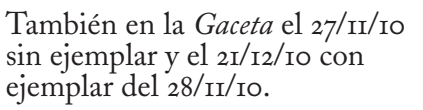 \\
\hline $\begin{array}{l}\text { Trinidad Wee- } \\
\text { kly Courant } \\
\text { (de Mateo } \\
\text { Gallagher) }\end{array}$ & Trinidad & 2I/I2/IO & 24/II/IO & $\begin{array}{l}\text { Posiblemente se trate del Tri- } \\
\text { nidad Courant en la Gaceta del } \\
\text { 2/o7, Gazeta de Trinidad o Gazeta } \\
\text { Courant, ambos nombres en la } \\
\text { edición del } 5 / \text { o } 7 / \text { I de la Gaceta de } \\
\text { Caracas; la última con ejemplar } \\
\text { del } 29 / \text { o5/Ir. Inferimos que se } \\
\text { trata de la misma por la diatriba } \\
\text { con The Independent publicada el } \\
\text { 5/o7/II en la Gaceta. }\end{array}$ \\
\hline
\end{tabular}


Louisiana I5/I/II 26/10/IO

$(\dot{2})$

108

\begin{tabular}{|c|c|c|c|c|}
\hline $\begin{array}{l}\text { St. Thomas } \\
\text { Monday's } \\
\text { Advertiser }\end{array}$ & St. Thomas & I8/OI/II & $\mathrm{I} 2 / \mathrm{II} / \mathrm{IO}$ & $\begin{array}{l}\text { También con el nombre Gaze- } \\
\text { ta de St. Thomas el 4/o6/II y } \\
\text { el I4/o5/II con ejemplares del } \\
\text { I5/o5/II y el 20/03/II respectiva- } \\
\text { mente. }\end{array}$ \\
\hline The Examiner & Londres & $25 / \mathrm{OI} / \mathrm{II}$ & I9/II/IO & $\begin{array}{l}\text { Revista. } \\
\text { No tiene otras apariciones en la } \\
\text { Gaceta. }\end{array}$ \\
\hline
\end{tabular}
$\begin{array}{llll}\begin{array}{l}\text { Gazeta de } \\ \text { Jamaica }\end{array} & \text { Jamaica } & \text { I5/o2/II } & \text { Con el nombre de Jamayca de } \\ \text { Courant } \mathrm{el} \mathrm{I} / \mathrm{IO} / \mathrm{II} \text { con ejempla }\end{array}$ del ro/ri/ıo Como Jamayca

Courant, el I2/o3/II.

Como Gazeta Real de Jamaica el 25/06/Ir con ejemplares del 23 al 26 de marzo.

\begin{tabular}{|c|c|c|c|c|}
\hline $\begin{array}{l}\text { Monitor } \\
\text { extraordinario } \\
\text { de Luisiana }\end{array}$ & Louisiana & $22 / 04 / I I$ & $\mathrm{~s} / \mathrm{e}$ & $\begin{array}{l}\text { También Moniteur de } \\
\text { la Louisiane. Edición } \\
\text { extraordinaria. }\end{array}$ \\
\hline
\end{tabular}

Se hace una referencia al Monitor el 4/o6 en Gaceta.

\begin{tabular}{lll}
\hline Gazeta de New Nueva York 22/04/II & 7/03/II & $\begin{array}{l}\text { Puede tratarse de New York } \\
\text { Herald, pero no tenemos noticias } \\
\text { York }\end{array}$ \\
& que los relacionen.
\end{tabular}

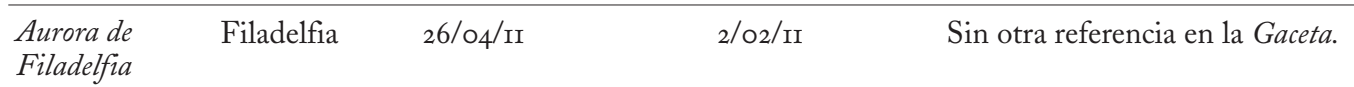

Gazeta de la Pointe à Pitre, 4/06/II 7/03/II Sin otra referencia en la Gaceta.

Pointe à Pitre Guadalupe

\begin{tabular}{|c|c|c|c|c|}
\hline $\begin{array}{l}\text { Gazeta de } \\
\text { Martinica }\end{array}$ & Martinica & 4/O6/II & 2I/O5/II & $\begin{array}{l}\text { También referida en la edición } \\
\text { del } 4 / \text { o6/II con ejemplar del } \\
\text { 2I/o5 y en la edición del 3/o5/ıo } \\
\text { con ejemplar del I5/o3/II. Ver } \\
\text { Comercial Gazette en este caudro. }\end{array}$ \\
\hline
\end{tabular}

\begin{tabular}{|c|c|c|c|c|}
\hline $\begin{array}{l}\text { O Correio } \\
\text { Braziliense }\end{array}$ & Londres & I8/06/II & s/e & $\begin{array}{l}\text { También el 2I/o6/II sin ejemplar. } \\
\text { Se le denomina "periodico } \\
\text { portugués», quizás por la lengua } \\
\text { en que se escribe. }\end{array}$ \\
\hline
\end{tabular}




\begin{tabular}{|c|c|c|c|c|}
\hline $\begin{array}{l}\text { London } \\
\text { Packet }\end{array}$ & Londres & I8/o6/II & I5/O5/II & Sin otra referencia en la Gaceta. \\
\hline $\begin{array}{l}\text { New York } \\
\text { Herald }\end{array}$ & Nueva York & 2/OF/II & $\mathrm{s} / \mathrm{e}$ & Sin otra referencia en la Gaceta. \\
\hline $\begin{array}{l}\text { Comercial } \\
\text { Gazette }\end{array}$ & $\begin{array}{l}\text { Trinidad (¿?) } \\
\text { Martinica (¿?) }\end{array}$ & 2/OF/II & $\mathrm{s} / \mathrm{e}$ & $\begin{array}{l}\text { Inferimos los lugares de la } \\
\text { mención junto con Trinidad } \\
\text { Courant o bien puede tratarse de } \\
\text { la Gazeta Comercial de Martinica, } \\
\text { en la edición del 4/o6/Ir y el } \\
\text { 3/o5/1o con ejemplar del 2I/05 y } \\
\text { el I5/o3/II respectivamente. }\end{array}$ \\
\hline $\begin{array}{l}\text { The } \\
\text { Independent } \\
\text { Gazette }\end{array}$ & Londres & $5 / 07 / \mathrm{II}$ & I8/06/II (i?) & Sin otra referencia en la Gaceta. \\
\hline
\end{tabular}

Para efectos de orientación y persuasión ideológica advertimos en la Gaceta el uso de sentencias latinas como referencias para el diálogo entre redactores-lectores ideales cuya interacción es en ocasiones explícita mediante las contestaciones de cartas o reflexiones sobre artículos publicados. En algunos casos se detalla la fuente de la sentencia, en otros, es sobreentendida pero, a menos que se demuestre lo contrario en la comparación de textos de origen y textos traducidos, en ningún caso el latín es objeto de traducción, lo que evidencia el manejo de éste entre quienes acceden al discurso periodístico. La intertextualidad se establece entonces, por el sentido tácito que conlleva la referencia del autor o la sentencia que se utiliza y que funciona en ocasiones para orientar el tema central del manuscrito. Durante el periodo de octubre de I8Io a julio I8II se presentan diez textos con referencias en latín; en su mayoría en el Manifiesto de Santa Fe (I/I/II) o sobre el gobierno de Santa $\mathrm{Fe}$ (04/06/II), papeles dirigidos a la Suprema Junta de Cartagena (25/06/II) y los escritos en oficios del Nuevo Reyno de Granada (4/I2/ıo y 26/O4/II).
Relativos a la Provincia de Caracas se hallan dos artículos en la ocasional columna «Discurso político» (II/OI/II y 8/O2/II); el primero relativo a la protesta por el supuesto poder concedido por Fernando VII a la Regencia de Cádiz ya que no hay Cédula donde se delegue a ésta el gobierno de los dominios de «nuestro Soberano» y el segundo, sobre la opresión de Napoleón cuya dominación «se extiende hasta las columnas de Hércules». En éste, las referencias a Séneca y al «arte de engañar» de Agesilao soportan la idea del arte marcial de Napoleón: someter a los «Pueblos» al engaño para oprimirlos. Un tercer texto sobre el Duque Luis Felipe de Orléans (I9/02/II), expresa la defensa de Fernando VII en detrimento de «lo poco que desean los Gobiernos de España» la dominación de éste o algún representante de su familia. Cuatro textos más se sirven del latín: la carta del Marqués del Toro al Secretario de Guerra (I8/I2/Io); el artículo del «protoescritor de anónimos», texto redactado según Ratto Ciarlo (I97I) por el mismo cuerpo de la Gaceta en el que se parodia el discurso de un agente de la oposición encargado de «sembrar zizaña en 
toda Venezuela» (9/ro/ro); la Harenga pastoral del Arzobispo de Caracas, Narciso Coll y Prat (5/o3/II) y la conmemoración del ig de abril, en I8Ir. Se suma a este corpus las referencias a clásicos latinos utilizados por William Burke en su artículo sobre tolerancia religiosa (I9/O2/II).

Si bien podría señalarse a partir de los ejemplos expuestos que el latín no se traduce cuando sus fuentes provienen de periódicos o papeles americanos, observamos que esto también ocurre en papeles traducidos del francés, por ejemplo, en la «carta interceptada al Ministro Anzanza ${ }^{20}$ 》 ( $\left.19 / 03 / \mathrm{II}\right)$, cuya fuente es el periódico El Español, en la que la construcción de la imagen de Napoleón como «hombre de quod scripsi scripsi» (categórico e inexorable en sus decisiones) se pone en entredicho. En esta carta, las comunicaciones de alguien que hace pasarse por Duroc ${ }^{2 I}$ se traducen al español para demostrar, mediante el discurso referido, las dudas de Napoleón sobre la fidelidad de su ingrata familia. También se copian textualmente las palabras de, posiblemente, Denis Decrés, Ministro de Marina, en casa de Bassano ${ }^{22}$, junto con los incisos en español del autor para dar autenticidad al acontecimiento referido: «C'est une machine compliquée, fueron sus expresiones, dont la multiplicité des resorts pourrait nuire á l'harmonie et dont l'avantage d'un seul agent est absolument reconnu [...] al fin me dixo La chose est decidée la France a fait de grands sacrifices pour l'Espagne et la doit en être

${ }_{20}$ Miguel José de Anzanza. Militar español, Virrey de Nueva España, Ministro de Hacienda de Fernando VII y colaborador de José Bonaparte.

${ }^{21}$ Giraud Christophe Michel Durot. Al respecto, el autor de la carta dice: «Al instante conocí que no era Duroc el que hablaba, las ideas, las expresiones, y el modo, todo me hizo conocer que la cosa venia de mas arriba» (I9/O2/II).

${ }_{22}$ Hugues Bernard, Duque de Bassano, quien copia el mensaje imperial de Napoleón publicado en la Gaceta del I7/05/II.

dédommagée» ${ }^{23}$.

No obstante, desde una óptica diferente se configuraba la imagen de Napoleón desde Venezuela, un mes antes. En la edición de la Gaceta del I/o2/Ir la evaluación del traductor de la columna de «Noticias extranjeras» apuntaba sobre el Decreto Imperial: «La America libre debe tomar lecciones de la tirania del otro hemisferio para arreglar su constitución de un modo que no pueda ser accesible al despotismo militar que abruma á una Nacion que hace muy pocos años luchaba, como nosotros, por obtener la libertad que ha perdido tal vez para siempre». Sobre la traducción de este decreto se mantiene especial cuidado a conceptos como «rapport» $\mathrm{y}$ «surveillance», entendidos respectivamente como «relación del gran juez» o «Ministro de Policia» y «personas puestas baxo custodia». Siguen al decreto las observaciones que el redactor del Times hace sobre el decreto ${ }^{24}$.

Como el caso de Anzanza, la circulación de papeles revelados gracias a la intercepción y donde se halla la representación negativa del otro con intervención explícita del redactor se puede verificar en ediciones anteriores de la Gaceta; por ejemplo, el I3/II/Io, una nota editorial revela la llegada de estos papeles: «Ahora empiezan á llegar á nuestras manos los papeles que procurò interceptar la Regencia quando prohibiò que leyesemos otra Gazeta que la suya». Queda así expuesta la censura a la que se sometía la redacción del periódico hacia finales de 1808 cuando Sir John Moore escribe la carta a favor de la causa patriótica. Así el Extracto refiere

La imbecilidad del Gobierno Español, excede toda imaginación. La buena voluntad

${ }_{23}$ La fuente de esta carta es el periódico El Español, de Blanco White.

${ }^{24}$ La nota del redactor de la Gaceta deja explícita constancia de que son ellos quienes han traducido el decreto a partir de la edición del 23 de marzo del Times. 
de los habitantes es inútil, mientras que no haya quien tenga la habilidad para ponerla en movimiento [...] Los pobres Españoles merecen mejor suerte, por que parecen buenas gentes; pero han caido en manos que los han perdido por su apatia y su... aquí hay una supresión en la carta publicada. Si hubiese conocido antes la debilidad de los exercitos Españoles, el estado indefenso del pais, la apatia aparente del pueblo, y la egositica imbecilidad (selfish imbecility) del gobierno, no me hubiera apresurado à entrar en España.

Intervienen aquí dos evaluaciones: la de Sir Moore, que da cuenta sobre su apreciación del acontecimiento y el del redactor que deja su huella lingüística mediante las evaluaciones marcadas en el texto «aquí hay una supresión en la carta». También destaca el empleo de la expresión fuente («selfish imbecility») y el comentario final del texto que justifica su publicación y que añade nueva información, presumiblemente sobreentendida en el contexto en el que se publica: «Sir John Moore escribió estas cartas oficiales [...] en I808, lo que prueba que entonces se dudaba ya que la Junta fuese capaz de salvar la Patria y que no se ha empezado à dudar à la fin [énfasis mío] de r809 como el Consejo de Regencia pareciera insinuar». Seguidamente, sobre dos Generales, Bueno y Escalante, que intervienen en las Juntas se expresa: «me parecen dos debiles viejos, o por mejor decir dos viejas [énfasis en original], con los que no huviera sido posible concertar alguna operación militar» ${ }^{25}$.

Otras traducciones de testimonios de hom-

25 Como apunta la Gaceta, la fuente de la evaluación de estos dos Generales no se halla en la carta interceptada, sino en los «Extractos del discurso del Marques de Wetterley tomados del Morning Chronicle, y del Times, de zI de Marzo", pero que por su relación a la carta de Sir John Moore decidimos referirla en esta sección para efectos de la representación negativa en la traducción de papeles. bres públicos se presentan en las ediciones del 02/04/Ir y el I7/05 sobre el Duque de Cadore, a propósito de la intercepción al Ministro Anzanza. El 2/o4 en la que suponemos una carta de «Champagny, Duque de Cadore ${ }^{26}$, se trata la representación del otro. Inferimos que es una traducción porque se fecha en París, por el uso del «Nosotros» y porque se relaciona con los documentos de la edición de 17 de mayo donde se presentan traducciones de «noticias extranjeras» en la Gaceta. La carta expresa: «Todo se encuentra en el ilimitado poder de nuestro augusto hermano Napoleón, y la Francia solamente es capaz de acabar la obra empezada en España, y de hacerla feliz y venturosa». En la edición del I7 de mayo se presentan documentos del Senado Conservador de Francia, uno de ellos firmado por Napoleón y otro por el Ministro de Relaciones Exteriores, Duque de Cadore en los que cada texto lleva entrecomillado y sin intervención del traductor.

De forma similar, sin comillas, se presentan la Proclama de Jerónimo de Napoleón cuando es destronado por su hermano y cuyo tema es la exhortación a la fidelidad «para el auxilio del Emperador de los franceses» (2/o7/II). Cinco meses antes, el 12/o2 una comunicación de Luis Napoleón al cuerpo legislativo sobre la irritación de José con él, es traducida en la Gaceta sin el entrecomillado pero sí con una nota del redactor que advierte a partir de los «anales del despotismo» las acciones de Napoleón contra su hermano, el «repudio de su muger», la fuga de Luciano por no querer dar a su hija en «matrimonio violento [para] acelerar la destrucción de la España». La incorporación de estos documentos oficiales, más allá de ser pertinentes o no a la causa patriótica para hallar en los lectoCadore. 
res filiación política, demuestra por primera vez el acceso a estos papeles como fuente directa para la orientación de la función crítica del lector y no sólo como discurso referido en artículos de los traductores-redactores.

Así como se insertan en la Gaceta los escritos y la parodia discursiva del "protoescritor de anónimos», sembrador de cizaña, y de los relativos al opresivo Emperador francés, se halla en la Gaceta otro texto traducido, esta vez del inglés en el que se da cabida a "Un diario de oposición» que reporta la discusión en el Parlamento sobre la posibilidad de crear una Regencia en el principado de Gales por causa de la enfermedad del Príncipe. El artículo sin fuente destaca entre comillas la «protexta Real [...] firmada por los Duques de York, Clarence, Kent, Cumberland, Susex, Cambridge y Gloucester» y va precedido de la evaluación de quien inserta el extracto: «la siguiente noticia de un papel que se supone interesado à favor de los amigos del Principe». En este sentido, no podemos determinar con certeza si la traducción proviene del diario o es realizada por el cuerpo de redactores de la Gaceta.

En cuanto a las referencias de autores encontramos una sola editorial de la Gaceta del 20/II/Io que representa en otra lengua la imagen de los americanos por su moderación «en sus justos resentimientos con mas heroísmo que la misma Regencia». Allí, el redactor acuña sobre la generosidad de los americanos relativos a los sucesos de España: "America [...] acaba de convencer al Mundo de lo que hace mucho tiempo dijo un Poeta Frances de los Américanos. L'Américain farouche, en sa simplicité Nous egale en courage, \& nous passe en bontè».

En los artículos del periódico y obras referidas, hallamos varias noticias que insertan a autores franceses e ingleses como recurso argumentativo para sustentar disputas sobre dos temas tratados por William Burke en sus escri-

tos, que convulsionaron al cuerpo eclesiástico y a algunos sectores mantuanos: la tolerancia religiosa y la independencia, tratados principalmente en las ediciones del I9/o2 y el 29/o3/II. Se suman las Reflexiones de Blanco White sobre la libertad de imprenta, el 2 y 30 de abril. Una sola referencia, discrepante con el resto, la hallamos en la «harenga pastoral» del nuevo Arzobispo de Caracas, Narciso Coll y Prat publicada el día 8/o3 con motivo de la creación del Congreso de Venezuela seis días antes; según Pino Iturrieta (I97I: 22I) es él «uno de los antagonistas más distinguidos de la revolución». Entre esta arenga y el decreto que fija el recién instaurado congreso se identifican las sutilezas del discurso político que da cuenta del contexto caldeado por los artículos de Burke sobre la libertad de cultos y la reafirmación de la adscripción de los representantes políticos a la religión católica. En su arenga Coll expresa, además de las reiteradas sentencias latinas:

Pero en medio de tanto jubilo, ¡que reunion de ideas se me representa! [...] Meditación profunda sobre las costumbres y habitudes de los naturales! Modos y resortes insensibles para habituarlos à su deber, á que sean unos Patricios verdaderos [...] Baxo estas esperanzas y deseos, una cosa me atrevo á suplicar à V.A.: soy el depositario de la Fé, soy el pastor de toda mi Grey [...] y he do (sic, de) ser el muro inexpugnable de la Ciudad! [...] la Religión [...] Aquella que siempre atenta al mayor servicio de Dios y de los hombres, es la mas aproposito para hacernos felices [...] como lo confiesa el Publicista y Filosofo, no sospechoso en la materia, Montesquieu, que infunde en los Magistrados las ideas mas puras y beneficas sobre la naturaleza de las funciones y deberes que deben llenar para con el Pueblo (8/o3/II).

Afirmamos en esta cita in extenso, el uso de la referencia a Montesquieu como recurso discursivo del que se vale Coll y Prat para sostener los 
buenos términos con los diputados del Congreso, quienes en el decreto que sigue a la publicación de la arenga responden : «No ha creido el Congreso que el M.R.A. dude por un instante de la certeza y verdad de los sentimientos Catolicos y Religiosos que le animan, que le distinguen, y de que hace un alarde publico [...] Venezuela ni sus legitimos representantes permitiran que se mancille con la mas leve nota, ni acto profano, la Religión que ha jurado defender pura é ilesa». De esta forma la referencia a los autores franceses no siempre está motivada por la búsqueda de ideales patrióticos sino más bien, como en este caso, obedece a intereses políticos.

De manera diferente ocurre con las protestas que se hacen en el Manifiesto de Santa $\mathrm{Fe}$ del r5/or contra la dilapidación del oro y la plata a costa del trabajo de trabajadores y artesanos, la ocupación de las propiedades de la Iglesia hecha por Godoy, el insulto hecho «con pluma mas atrevida que la de Dupin, y con tinta mas negra de que de Voltaire» al Obispo Gregorio Angulo, quien «exortaba a orar por la felicidad de las armas de España». En este texto se exhortaba a la libertad de los pueblos, pues «donde quiera que se junta un grupo de Europeos, se erige una soberanía sin tener autoridad, ni poderes para ello [...] nos quieren hacer vasallos ya de la Junta de Sevilla, ya de la Central, ya del Consejo de la Isla de Leon; y que quiza mañana nos querran hacer esclavos de Mallorca, de Ibiza, de Tenerife, o cualquier otro lugar donde se les antoje unir un puñado de gentes ambiciosas de dominación». Diez días después, las protestas de este manifiesto se basarán en el reclamo hacia el Gobierno español por querer mantener a América «en una profunda ignorancia» ante el intento de prohibición de los «derechos sagrados del hombre» en la Carta dirigida a los
Americanos ${ }^{27}$ y por la pena de muerte establecida para quienes reimprimieran los Derechos del Hombre traducidos por Antonio Nariño ${ }^{28}$.

En cuanto a las lecturas de Burke, son las 113 mismas las referencias textuales que sirven de base para contraargumentar los argumentos de éste, pero releídas por Antonio Gómez con el mismo cuido que el primero. Al respecto, en la contestación de carácter legislativo y filosófico de Gómez publicada o9/o4/Ir se halla la mención explícita a Rousseau, a partir de quien se hace una reinterpretación de sus planteos, pues si bien la lectura que hace Burke de Rousseau le permite explicar «la profesion de fé civil», Gómez utiliza el mismo argumento para justificar que «si la fuerza civil, que ocasiono el culto religioso exclusivo, se combinase con el impulso de la tolerancia de los demas cultos, su tendencia tornaria á sumergir la sociedad en el abismo primitivo de la diversidad de opiniones». De la misma forma, interpreta Gómez a Montesquieu, Humboldt, Thomas Cromwell, Locke y las referencias latinas.

Sobre los artículos de Burke afirmamos que el objetivo de ilustrar a través de la esfera pública o de instruir al Pueblo ${ }^{29}$ tan difundido por la Gaceta, se establece, precisamente, mediante la traducción explícita que se hace en sus textos así como en aquellos que publica, el que suponemos cuerpo de traductores-redactores que participan de la vida política venezolana. Principalmente en el marco legislativo, la función pedagógica queda en evidencia por las notas y comentarios que guían al lector sobre modelos extranjeros

27 En la edición del 25/or/rr la nota al pie de la Gaceta señala «Londres, I8oI». Inferimos que se trata de la carta de Juan Pablo Vizcardo y Guzmán. Acerca de la traducción de esta carta ver Bastin y Castrillón (2004).

${ }_{28}$ Acerca de la traducción de Nariño, ver Bastin y Echeverri (2004: 569).

${ }_{29}$ Se toma en el sentido que expone Miguel José Sanz en el Semanario de Caracas, tratado con anterioridad. 
que se presentan como referencia para quienes están en el proceso de construcción de nuevas representaciones institucionales y jurídicas. En 114 Burke esto se expone en sus artículos del 22/oI y I2/o2 en su columna Derechos de la America del Sur y Mexico en la que toma como ejemplo los Estados independientes de la «República de Norte America» que tienen leyes propias pero todos están «unidos por una Constitución y congreso General para la defensa comun», funcional para la «multitud de circulos politicos». En el artículo del I2/o2 a propósito de «la vida, libertad, y propiedad del vasallo en Inglaterra, y del ciudadano en los Estados Unidos» expone las actas contra los arrestos ilegales, la función de los «Sheriff» (carceleros), el «habeas corpus» $\mathrm{y}$ «Juicio por Julis» como «decisiones de la junta». Estos artículos van seguidos en ediciones posteriores por la disertación sobre la Camara de los comunes... y en Reglas de debate publicados respectivamente los días I9/o2 y 22/o2 de I8II pero no en la columna de Burke ${ }^{3 \circ}$. En éstos se hace referencia en notas, entre otros ejemplos, a términos extranjeros: al «speaker» (vocero), a la performatividad de éste en la «question de orden» para la toma de la palabra, a la posición contra el «trangresor», la función del «segunder», tal como expresa el traductor: «del verbo to second, y en francés, secunder [...] asi me parece que podra usarse en este caso». También los «bills», explicado por Burke en el artículo del 22/or como «estatuto o ley que se presenta al Parlamento», la «orden del día», los «dispuesto» como «disponer de una moción, algun acuerdo sobre ella», la ubicación de la «barra» de la cámara, la función de los «escrutadores», «pedir separación» (división), etc.; de tal manera que la traducción no sólo es vínculo

\footnotetext{
30 Comienza en esta columna su exposición sobre la tolerancia de cultos.
}

para acceder a otras representaciones institucionales en términos lingüísticos sino también para «cartografiar» sus espacios. Se suman a los artículos con fines políticos-instructivos, iniciados por Burke ${ }^{\mathrm{I}}$, las Reflexiones sobre libertad de imprenta, cuya fuente es en ocasiones el periódico de Blanco White El Español así como el Articulo comunicado en ingles publicado en las ediciones del 26/04/II, el 30/04 y el 3/ que, traducido al castellano, diserta sobre la libertad de imprenta y finaliza con la traducción (en cursiva) de la legislación de Jeremy Bentham «El rigor de la censura no servia [en Francia] sino para hacer transportar el comercio de libros á otras naciones, y hacer mas amarga la satira que ella debia suprimin» (30/04/II).

\section{REDES DE INFORMACIÓN SOBRE POLÍTICA AMERICANA Y EXTRANJERA} A TRAVÉS DE LA TRADUCCIÓN

La traducción sobre acontecimientos noticiosos del contexto político tiene, como se ha demostrado anteriormente, estrategias para el cuestionamiento y deslegitimación de quien se considere adversario. Un ejemplo atípico se halla en la «Noticias extrangeras» del 23/ro/ıo en la referencia sobre quienes gobiernan la America del Sur, reflexión de un «periódico inglés ${ }^{32} »$ aparecido en el Bell's Weekly Messenger

$3^{\text {I }}$ Luego del artículo sobre la tolerancia religiosa, en el que se insertan (valga la forma impersonal) la nota que exhorta al debate y a la publicación de otras reflexiones, se insertan en la columna las impugnaciones de Antonio Gómez el r6/o4 sobre los artículos de Burke, la conmemoración sobre el ig de abril (edición del I9/o4/II), el reclamo de la Junta Provincial de Mérida, firmada por su presidente, Antonio Picón y Mariano de Talavera, lo que deja en evidencia, tratándose la Gaceta de un periódico oficial, las reservas ante la posición asumida por Burke.

32 Por la fecha, tema, discurso y exposición podríamos adjudicarlo a El Colombiano, de Francisco de Miranda. 
$(B W M)^{33}$ que pareciera más bien responder a una crítica, de quien bien conoce los avatares intraprovinciales de Venezuela:

Los Gobernadores de la America del Sur, naturalmente desean retener y perpetuar presente su presente poder [...] Ellos por consiguiente gobernarian con gusto la America Meridional baxo el nombre de la autoridad de Fernando, porque saben que tal Gobernación seria sin responsabilidad ni restricción. Su lealtad seria un ofrecimiento barato, hecho á una fantasma (sic) y á un prisionero á distancia de tres mil leguas sin tributo ni sumision [...] Una soberania nominal seria un mero engaño para seducir al Pueblo; mientras que todo poder efectivo estaria en manos de aquellos que con un entero desprecio del mismo Monarca, serìan los que mas clamarian por la lealtad y obediencia de los otros [...] La forma de Gobierno conveniente en la America Meridional es mas bien la Republicana que la Monarquica.

También desde un "Nosotros» intragrupal en la edición del 30/II en la columna «Europa» y con el $B W M$ como fuente, se trata sobre la «suerte de Cadiz» y del «temor de hambre» en un puerto abierto así como el «verdadero temor» de que su guarnición no sea suficiente y sea compelida; además se señala «sentimos que la causa Española no esté de acuerdo con el Gobierno Español. No hay uno que rehuse a contribuir voluntariamente à la Guerra a favor del pueblo Español, y tampoco hay uno, hablando por nosotros mismos, que quiera hacer algo por el Rey Fernando ni por su corte [...] No apliquemos á los Españoles lo que en la era de la gloriosa revolucion de $\mathrm{i} 688$, rehusamos aplicarnos à nosotros mismos». No obstante, en nota que agrega la editorial de la Gaceta se acla-

33 Todas las referencias a la prensa extranjera provienen de las ediciones de la Gaceta, por lo que mantenemos la misma ficha hemerográfica de la Gaceta así como la grafía. ra la posición política que toma con respecto al «Soberano»: «La America Española ha tenido la generosidad de no controvertir los derechos de Fernando, quando tenia libertad de hacerlo [...] ha jurado conservarlos inmunes; jamas sera inconsecuente [...] jamas reconocera otra soberania».

En torno a Cádiz, el 6/ıI/ıo en una carta de un «español de Cadiz» del Morning Chronicle $(M C)$ expresa su asombro sobre el decreto del 30 de julio, en Cádiz, por el cierre del comercio de productos de Caracas, pues se observa «con placer» en los habitantes de ésta «un espiritu de moderacion en sus procedimientos», pero advierte que se trata de una medida porque «La Regencia supone que Caracas se ha declarado independiente de la Madre Patria» [...] calumnia que solo sirve para manifestar la falsedad de aquello de quienes procede [porque] Es notorio a todo el resto del Mundo que la Provincia de Venezuela se ha declarado independiente, no de la Madre Patria, no del Soberano, sino de la Regencia». A esto se responde con una nota del redactor que expresa sobre la región española: «nada nos importan sus bloqueos (a), sus escuadras, sus comisionados, y sus declaraciones de Guerra» sólo les importa no ser parte de los cálculos de Francia; además se evalúa con cierta ironía en nota al pie «(a) Parece que quitando una l. al bloquear de la Regencia, es lo que probablemente esta haciendo ahora».

Sobre esta filiación a la Regencia una «Carta de un caballero Ingles residente en Buenos Aires» del $M C$ publicada en Gaceta el II/I2/Io expone la adhesión de Montevideo a la Regencia y denuncia las «pretensiones» de la Reina de Portugal, la disposición para hacer concesiones a favor de Inglaterra y se afirma «que todo Español Americano querrá antes morir que someterse a los Portugueses». Diez días después se publica en Gaceta con el Phi- 
ladelphia Mercantile Advertiser (PhMA) como fuente un «artículo de (sic, sobre) una carta de Lisboa» de la que se cita entre comillas «se espera por momentos una batalla que decida la muerte de Portugal. Solo en las avanzadas y escaramuzas es que Lord Wellington ha ganado ventajas $\mathrm{y}$ ha hecho nacer esperanzas de su pericia para contener y encerrar el enemigo» (21/I2/1O). No obstante, cuatro días después, por el $M C$ en la edición de la Gaceta del 2I/12 el tratado de amistad entre el Príncipe Regente de Portugal y Gran Bretaña que permite a éstos cortar madera en todos los montes de Brasil, así como plantea medidas eficaces para abolir el comercio tiránico de esclavos y declara abolida la Inquisión en sus dominios de América.

Otra mención sobre la América se lee seis meses después en la fuente $O$ Correio Brazilense $(C B)$. A propósito del proyecto de constitución de la Florida ${ }^{34}$ se relaciona la unión de Sante Fe con Caracas y de forma similar, los pueblos del Río de la Pata con Buenos Aires, pese a que la ciudad de Córdoba se haya puesto contra Buenos Aires y Montevideo vaya contra sus dependencias. Este contexto le sirve de base para afirmar que "Caracas [...] seguira el impulso de sus justos resentimientos y la voz de sus verdaderos intereses, declarando la independencia que le corresponde, y que no ha declarado aun por pura generosidad, mayormente cuando conoce que el Gobierno de España no tiene fuerzas para subyugarla por violencia» (I3/6/II); independencia que ocurre en Venezuela tres semanas después.

Otras nacientes naciones americanas serán leídas también por la extensa cadena de infor-

34 Situación política tratada en la Gaceta en ediciones del r3/II/I y 21/12/Io por noticias del Times y el Trinidad Weekle Courant $(T W C)$ respectivamente.

mación, por ejemplo, como se señaló anteriormente, en abril, el 22, México es referido por la Gazeta de New York, artículo traducido por el Monitor de Luisiana. También se trata la «arrogancia mexicana» en un escrito de la Gaceta de Jamaica referido por la Gaceta de México, cuyo artículo se presenta en Gaceta el 25/06/rr. En abril se publican noticias sobre Nueva York que se leen a partir de la Aurora de Philadelphia presentada en la Gaceta el día 26. En mayo leemos sobre Perú el día I4 y sobre Perú y Martinica el 2I del mismo mes a través del Relf's Philadelphia Gazette y la Gazeta de Martinica respectivamente.

En cuanto a la forma de imaginar la nación venezolana es primordial la referencia a la prensa del Caribe, que en el caso de Trinidad refiere a la America como «continente de al lado». En esta prensa se presentan dos aspectos en cuanto a traducción y representación: la coincidencia de fuentes para el reporte de noticias sobre Cuba y los conflictos entre los grupos de quienes escriben en estos medios, dado paradójicamente, por el tema sobre las rivalidades interprovinciales entre Caracas y Cumaná en Venezuela. Por una parte, el Argos Americano de Cartagena $(A A C)$, referido por la Gaceta el 22/02, presenta en la sección Kingston de Jamaica, el conocimiento que se tiene sobre la formación de una Junta como forma de gobierno en la Isla de Cuba; noticia que se continúa en la edición del ז/o3 con fuente del Jamaica Courant. En este último se exponen exactamente en el mismo orden los motivos para esta decisión tal como se presentaran en la edición del 22 a través del Argos, lo que puede aludir a que tanto este periódico como el Courant hayan tenido la misma fuente, escrita en castellano o ya traducida o que uno de los dos haya fungido como fuente del otro, pues no hay garantías de que el primer artículo publicado haya sido el primero producido. No 
obstante, el Courant cita textualmente el oficio donde esta decisión se declara y se trata la figura de Godoy como oportunista, opresora y a los ilustrados de las audiencias como langostas devoradoras (I/oz/II).

Por otra parte, se plantea el conflicto entre periódicos por la información tratada sobre las supuestas desavenencias entre las provincias de Cumaná y Caracas. En la Traducción de Carta de un Hacendado de Guiria al Editor del Periodico Trinidad Courant $(T C)^{35}$, publicada por la Gaceta el 7/05/II, se detalla un complot en Cumaná ideado por «los Europeos», y que condujo por venganza querer el «exterminio de los Criollos». Así se expresa en la carta: «En las revoluciones politicas, hay siempre mas o menos enemigos domesticos que minan el estado; pero un exceso de traidores $[\ldots]$ no pueden mencionarse en las historias, y excede a todas las vielezas (sic) del genero humano [...] la mascara de la hipocresía se cayo muy pronto». Esto produce que el gobierno se haya visto, según el manuscrito, en la necesidad de arrestar «a todos los Europeos comprendidos en ella, $[\ldots]$ secuestrar sus propiedades [...] y proceder luego a su relegacion». Ello demuestra que, para el escritor del texto, el proceso independentista no era homogéneo ni unánime dentro del territorio venezolano o al menos así pretendió difundir la idea.

Esta situación se relaciona con dos cartas publicadas luego, una en la edición de la Gaceta del 2/o7 y con fuente del $T C$, en la que se exponen los avances comerciales en la Provincia de Cumaná establecido por el cuerpo legislativo formado el ig de junio. Entre los cambios positivos se hallan la libertad de comercio, inclusive con España, la anulación de arresto por sospecha del código criminal así como el secuestro

35 Como lo expresa el título, suponemos que esta carta fue redactada en castellano y luego traducida al inglés. de bienes, aunque remarcan la partida de los «Españoles Europeos» a Puerto Rico por la suspensión del bloqueo que había hecho el gobierno de esta Isla. En la segunda carta, Extracto de un Capitulo inserto en la Gazeta de Trinidad, del 29 de mayo motivado por un oficio comunicado por el Gobierno de Cumaná al Gobierno de Puerto Rico, se señala la proclamación para reunir a dichos españoles sea cual fuere su condición dentro del territorio, así como también se le declara a Venezuela y Cumaná en estado de «Insurrección y rebelión» y se concluye con la deslegitimación del proceso político venezolano de la siguiente forma: «Es tiempo con los ejemplos delante de nuestros ojos, despertar de nuestra letargia, y no ser los bobos de estos caracteres que no solamente se permiten entre nosotros, pero por fatalidad se recompensa su apostasia y audacia» (5/o7/II).

Es la traducción «en muy mal castellano» mediante la que, en palabras del redactor del Gaceta, se permite mostrar el discurso original del Trinidad Courant al mismo tiempo que se justifica el mal uso de la lengua por parte de The Independent como forma de respeto y neutralidad en tanto vínculo noticioso. Así el redactor de la Gaceta procede a catalogar The Independent como "periodico [...] vendido hace mucho tiempo a nuestros enemigos», rescata la imagen de los «desgraciados Realistas de la Costa Firme» o bien «pobres Realistas» (expulsados a Puerto Rico) y procede, en su primera nota al pie, a declarar:

Si el Redactor, ó el Autor del Discurso, respetara como debe los generosos principios de su nacion veria que ella misma ha reconocido que los Caraqueños y Cumaneses son mas fieles á sus promesas que los que quiere defender el Redactor, puesto que el Gobierno de Trinidad ha declarado como perturbadores del orden publico á los [Españoles Europeos] que despues de haber jurado un Gobierno han 


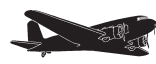

conspirado contra el, y despues de no haber sufrido otro (sic) pena que la de abandonar el pais que quieren sacrificar, han abusado de la hospitalidad que recibieron en otro para tramar nuevas conspiraciones.

Sobre esta representación negativa adjudicada al Gobierno de Trinidad por parte del redactor de la Gaceta, el redactor del artículo del Courant apela a los gobiernos coloniales y construye sobre el desempeño de los cumaneses: «Hermanos Colonistas, alguno de vosotros ha visto cosa semejante? Este mismo Gobierno Supremo (¿quantos Gobiernos Supremos tendra esta gente?) de Cumana parece que esta aun en mantillas en asuntos de diplomacia [...] revolucionarios son siempre lo mismo en todas partes; tormentados con sospechas eternas, esperando de los neutrales mas de lo que debieran, siempre ansiosos del Robo, y siempre dados a la maledicencia». Estas palabras fueron catalogadas por la Gaceta como «fárrago de politica y moral».

Una vez depuesta la primera República, el espacio público todavía se resiente sobre estas ideas dadas por la circulación de los textos que indujeron el nuevo espíritu preindependentista, por ejemplo, con la prédica que hiciera en I8I6 Salvador García Ortigoza en un sermón dado en la Iglesia Metropolitana de Caracas, tituladas luego como Pláticas doctrinales: «Tales son esos impíos escritores Voltaire, Rousseau, Montesquieu, toda esa gavilla de revolucionarios que alarman el pueblo contra el trono [...] esos libros que aquellos detestables caudillos pusieron en vuestras manos [...] Constituciones del Congreso de Venezuela [...] escritos de Guillermo Burke, Derechos del hombre [...] en una palabra, todos los impresos, proclamas y discursos, invectivas contra el Rey y Nación española, gacetas» (García Ortigosa citado en Pino Iturrieta, I998: 60).
También Andrés Bello, quien iniciara la Gaceta como redactor y traductor referirá, en $E l$ Araucano del io de mayo de I883:

Pocos ignoran [...] que bajo el régimen español tan celoso y suspicaz...circulaban clandestinamente en América, como en España, las obras de todos los corifeos de la incredulidad y las producciones más exaltadas de los publicistas liberales y republicanos, perseguidas aun más despiadadamente que aquellas. Voltaire, Rousseau, Helvecio, Montesquieu, no aguardaron el grito de la independencia para salvar la triple valla de nuestros resguardos y adunas. Sus escritos eran entonces más buscados y leídos que ahora, a pesar de las relaciones, las visitas domiciliares y todos los terrores de la policía inquisitorial (Bello citado por Leal, op. cit., Io6).

\section{PRIMERAS CONCLUSIONES}

Los autores, textos e ideas encuentran mediante el ejercicio de la traducción en la Gaceta una forma de contrarrestar la censura y adecuar los referentes de las metrópolis a una identidad incipiente en un contexto socio-político intelectual. La traducción como performatividad discursiva puso en evidencia el caleidoscopio de reflexiones que definían el incipiente ser nacional: la vacilación entre la fidelidad a la Junta o a la Regencia, la censura a Napoleón y el impacto y proceso de vínculos o autonomías, que dadas por las redes de sentido, se establecían en relación con la metrópoli y se transmitían, por las traducciones, a otros espacios americanos y a Venezuela.

Aunque no podamos aún afirmar con precisión, a partir de los ejemplos de prensa analizados, si los criollos venezolanos se nutren de las ideas de la revolución francesa para generar su propia revolución, consideramos que las lecturas de autores en obras bien aceleraron esta posibilidad. No obstante, es el contacto con la prensa inglesa y estadounidense la que 
pareciera ser en este periodo la promotora de las ideas y representaciones utilizadas por la elite para cartografiar sus propios espacios y referentes identitarios ${ }^{36}$, pues en cuanto a la traducción de papeles o personajes franceses la Gaceta sólo transmite representaciones negativas.

En cuanto al rol del traductor podemos señalar que es a partir de i8II cuando comienza a perfilarse su ejercicio en la prensa y éste hace uso explícito de la palabra para referir las selecciones que utilizan con el fin de instruir (por intereses políticos o por denuncia) a los lectores de la esfera pública sobre procesos jurídicos, complots, diatribas y debates. No se trata entonces de un ejercicio independiente, sino de una masa (elitesca) de autores críticos que como grupo social reflexionan sobre las formas de representación que se adecuan a nuestro contexto. Esto más allá de parecer una estrategia de control, es parte de la recreación dada a través de la escritura que entabla siempre diálogos implícitos con otros lectores-traductores de otros espacios.

RECIBIDO EN ENERO 2008 ACEPTADO EN FEBRERO 2008

\section{BIBLIOGRAFÍA}

Academia Nacional de la Historia (I983). La Gaceta de Caracas. Caracas: Biblioteca de la Academia Nacional de la Historia.

Academia Nacional de la Historia (1959). El Publicista de Venezuela. Caracas: Academia Nacional de la Historia.

Academia Nacional de la Historia (1959). Semanario de Caracas. Caracas: Academia Nacional de la Historia.

Anderson, B. (1993). Comunidades imaginadas. México: Fondo de Cultura Económica.

$3^{6}$ Acerca de la comparación entre influencias norteamericana y francesa, ver Bastin y Echeverri (2004: 572).
Ávila, F.J. (I964a). «Breve historia del periodismo caraqueño». En Materiales para el periodismo en Caracas (I808-I864). Caracas: Publicaciones del Secretaría General, pp. 9-16.

- (I964b). «La Gazeta de Caracas, primer periódico de Venezuela». En Materiales para el periodismo en Caracas (1808-1864). Caracas: Publicaciones del Secretaría General, pp. 29-36.

Bastin, G. L., y Castrillón, E. R. (2004). «La Carta dirigida a los españoles americanos, una carta que recorrió muchos caminos...» HERMENEUS, 6, pp. 273-290.

Bastin, G. L., y Echeverri, Á. (2004). «Traduction et révolution à l'époque de l'indépendance hispanoaméricaine». META, 49(3), pp. 562-575.

Bastin, G. L., Echeverri, A. y Campo, A. (2004). «La traducción en América Latina: propia y apropiada». En Estudios. Revista de Investigaciones Literarias y Culturales, 24, pp. 69-94.

Boada Alvis, J. (1964). «Un periódico que nació para defender a un Rey y murió con el nacimiento de una República». En Materiales para el periodismo en Caracas (I808-I864). Caracas: Publicaciones del Secretaría General. pp. 5I-56.

García Chuecos, H. (1964). «Un olvidado redactor de la Gaceta de Caracas». En Materiales para el periodismo en Caracas (1808-1864). Caracas: Publicaciones del Secretaría General, pp. 2I-24.

Grases, P. (I964). «La dos grandes noticias de la Gazeta de Caracas, el I9 de abril de i8io y el 5 de julio de I8II». En Materiales para el periodismo en Caracas (1808-1864). Caracas: Publicaciones del Secretaría General, pp. 47-50.

- (I979). De la imprenta en Venezuela y algunas obras de referencia. Caracas: Facultad de Humanidades y Educación, Universidad Central de Venezuela.

- (I983). «Estudio preliminar». En Academia Nacional de la Historia (1983). La Gaceta de Caracas. Caracas: Biblioteca de la Academia Nacional de la Historia. pp. xviI-LVI.

Guerra, F.X. (200I). Modernidad e independencias. México: MAPFRE y Fondo de Cultura Económica.

- (2002). «Voces del pueblo. Redes de comunicación y orígenes de la opinión en el mundo hispánico (I808-I8I4)». Revista de Indias, 2002, LXII, 225, pp. 357-384.

Habermas, J. (1997). Historia y critica de la opinión pública. México: Ediciones G. Pili. 
Langue, F. (2000). Aristócratas, honor y subversión en la Venezuela del siglo XVIII. Caracas: Biblioteca de la Academia Nacional de la Historia.

120

Leal, I. (2002). El primer periódico de Venezuela y el panorama de la cultura en el siglo XVIII. 229. Caracas: Academia Nacional de la Historia.

Lépinette, B (2003a). «Presentación». En Brigitte Lépinette y Antonio Melero (eds.) Historia de la traducción. Quaderns de Filologia. Estudis Lingüistics, III. pp. 69-9I.

- (2003b). «Traduction et histoire». En Brigitte Lépinette y Antonio Melero (eds.) Historia de la traducción. Quaderns de Filologia. Estudis Lingüistics, 3, pp. 69-9I.

Lynch, J. (200I). «El Estado colonial en Hispanoamérica». En América Latina, entre colonia y nación. Barcelona: Crítica. pp. 75-93.

Machado, J.E. (1964). «La Gazeta de Caracas». En Materiales para el periodismo en Caracas (I808I864). Caracas: Publicaciones del Secretaría General, pp. I7-20.

Méndez Salcedo, I. (1995). Seis temas de Historia de Venezuela. Caracas: s/e.

- (2002) La Capitanía General de Venezuela I777I82I. Caracas: Universidad Católica Andrés Bello-Instituto de Investigaciones Históricas / Universidad de Los Andes-Grupo de Investiga- ción sobre Historiografía de Venezuela.

Ortiz, F. (2002 [1940]). Contrapunteo cubano del tabaco y del azúcar. Madrid: Cátedra.

Pérez Vila, M. (1983). «Estudio preliminar». En Academia Nacional de la Historia (1983). La Gaceta de Caracas. Caracas: Biblioteca de la Academia Nacional de la Historia, pp. XI-LVIII.

Picón Salas, M. (1984). Formación y proceso de la literatura venezolana. Caracas: Monte Ávila editores.

Pino Iturrieta, E. (197I). La mentalidad venezolana de la emancipación (I8IO-I8I2). Caracas: Instituto de Estudios Hispanoamericanos/Facultad de Humanidades y Educación, Universidad Central de Venezuela.

- (I998). Ideas y mentalidades de Venezuela. I79. Caracas: Biblioteca de la Academia Nacional de la Historia.

- (2000). Fueros, civilización y ciudadanía. Caracas: Universidad Católica Andrés Bello.

Rama, Á. (1987). "Literatura y cultura». Transculturación narrativa en América Latina. México: Siglo XXI, pp. $\mathrm{II}^{-} 56$.

Ratto, Ciarlo, J. (I964). «El primer colaborador en la prensa venezolana». En Materiales para el periodismo en Caracas (1808-1864). Caracas: Publicaciones del Secretaría General, pp. 57-66.

- (1971). Libertad de prensa en Venezuela. Caracas: Biblioteca de Historia del Ejército. 